\title{
COMPORTAMENTO INDIVIDUAL E COOPERATIVO: FICHAS DE OBSERVAÇÃO
}

\author{
Maria Inês Abranches O. S. Fernandes
}

A observação dos comportamentos de crianças e adolescentes é sempre uma grande preocupação para os pesquisadores, professores e terapeutas em geral. Sabe-se que qualquer estratégia nesta área deve ser bem elaborada, planejada, e a mais abrangente possível, para ser um instrumento fidedigno, tanto nas pesquisas científicas, como em salas de aula e consultórios. Porém é importante ressaltar que as estratégias utilizadas devem ser práticas e de fácil manejo.

Em seu mestrado (Fernandes, 2000) propôs e testou a fidedignidade de uma categorização de respostas e de uma ficha de registro. Estas fichas de observação aqui sugeridas, fizeram parte do referido trabalho de pesquisa sobre Redação individual e em cooperação com sujeitos com dificuldades de aprendizagem escolar e foram utilizadas na observação dos comportamentos dos sujeitos trabalhando de forma individual e em cooperação com seus pares. A autora inspirou-se em Carvalho $(1995,1997)$ que descreveu os comportamentos dos sujeitos em sala de aula, durante o desenvolvimento da escrita cooperativa.

Para o Pré e Pós-Testes foi elaborada uma ficha de observação, denominada Ficha de Observação de Colaboração I Participação do sujeito em relação ao pesquisador e constou de 12 categorias que referiam-se à cooperação dos sujeitos de forma individual, em relação à pesquisadora, durante as atividades de produção de textos. Estas categorias estão exemplificadas a seguir.

Categoria 1: Atende às solicitações feitas - Compreende a resposta emitida pelo sujeito em atenção às solicitações feitas pela pesquisadora. Exemplo: "Tema livre é assim, escreve o que quiser, é livre".(S3, Pré-Teste).

Categoria 2: Colabora - Apresenta comportamentos de colaboração genérica e apoio geral em relação à pesquisadora. Exemplo: "A D. não vai completar aquela ficha, - que os outros completaram?" (S9, Pré-Teste, referindo-se à ficha de identificação, lembrando à pesquisadora para completar a ficha de sua dupla.)

Categoria 3: Expressa humor - Faz comentários que expressem situações de humor com relação ao grupo, a algum membro, ou à pesquisadora e à auxiliar de pesquisa. Exemplo: "O ostô com color" (Eu estou com calor) e seu par responde: "logo o vontolodor" (Ligue o ventilador) "Nós estamos falando na língua do o" e o grupo todo sorri. (S7 e S8, Pré-Teste).

Categoria 4: Expressa opinião - Faz comentários relacionados às atividades solicitadas pela pesquisadora. Exemplo: "Eu prefiro Tema Livre, pois vai que você dá um tema que eu não sei fazer e eu tenho um tema pronto na cabeça, aí é mais fácil..." (S2, Pós- Teste).

Categoria 5: Expressa satisfação - Apresenta comportamentos que demonstrem satisfação, prazer com relação às atividades propostas pela pesquisadora. Exemplo: "Gostei do tema, que legal, ah se eu tivesse asas..." (S2, Pré-teste).

Categoria 6: Faz solicitações/pedidos - Faz alguma solicitação ou algum pedido relacionados às propostas feitas pela pesquisadora. Exemplo: "É asa de anjo? Pode pegar um pedaço de um 
filme?" (S8, Pré-Teste).

Categoria 7: Inicia e mantém conversação - Se inicia diálogos com algum membro do grupo, com a pesquisadora ou auxiliar de pesquisa. Exemplo: "Lembra do tema que a gente fez da outra vez? Era um piquenique embaixo d'água, não era?" (S8, Pré-Teste).

Categoria 8: Oferece informação/ajuda - Se oferece ajuda a algum membro do grupo, à sua dupla ou para facilitar as explicações dadas pela pesquisadora. Exemplo: "Você conseguiu achar o tema? Pega aquela história..." (S7, Pré-Teste, oferecendo ajuda à sua dupla.)

Categoria 9: Pede retroinformação/(feedback) - Se após alguma explicação dada pela pesquisadora, solicita alguma outra informação, ou se necessita de alguma explicação para realizar sua atividade. Exemplo: "Ontem li uma história da Bíblia de Crianças; posso escrever esta história no Tema livre? (S1- Pré-Teste).

Categoria 10: Responde perguntas feitas pela pesquisadora - Observar se as perguntas são respondidas, no momento em que a pesquisadora as solicita. Exemplo: "Você está fazendo um romance?". "Sim, vou fazer, vai ficar maior ainda". (pesquisadora perguntando a S10, Pré-Teste, quando este sujeito se refere ao seu texto, dizendo que está longo)

Categoria 11: Pede explicação - Observar se os sujeitos solicitam outras explicações além das forneci das pela pesquisadora. Exemplo: "Posso começar assim, Se eu tivesse asas..." (S6, PréTeste, solicitando mais explicações à pesquisadora.)

Categoria 12: Pede informação - Observar se os sujeitos pedem alguma informação além das fornecidas pela pesquisadora. Exemplo: "Pode ser um poema, onde no final todas as frases rimassem?" (S9, Pós-Teste, solicitando outras informações para pesquisadora.)

Exemplo: "Você vai colocar estes textos no seu livro?" (S7, Pós-Teste.).

Além das notas, a pesquisadora e a auxiliar de pesquisa anotaram exemplos, procurando descrever os comportamentos de colaboração e os comentários dos sujeitos. A ficha de observação é apresentada a seguir.

Ficha de Observação/Participação do Sujeito em relação à pesquisadora.

Sujeito: Par: Situação:
\begin{tabular}{|l|l|l|l|l|l|l|}
\hline Colaboração/Participação em relação ao pesquisador & 1 & 2 & 3 & 4 & 5 & 6 \\
\hline Atende à solicitações feitas & & & & & & \\
\hline Colabora & & & & & & \\
\hline Expressa humor & & & & & & \\
\hline Expressa opinião & & & & & & \\
\hline Expressa satisfação & & & & & & \\
\hline Faz solicitações / pedidos & & & & & & \\
\hline Inicia e mantém conversação & & & & & & \\
\hline Oferece informação/ajuda & & & & & \\
\hline Pede retroinformação (feedback) & & & & & \\
\hline
\end{tabular}




\begin{tabular}{|l|l|l|l|l|l|l|}
\hline Responde perguntas feitas pela pesquisadora & & & & & & \\
\hline Pede explicação & & & & & & \\
\hline Pede informação & & & & & & \\
\hline
\end{tabular}

A pesquisadora durante a observação dos sujeitos, contou com a ajuda de uma auxiliar de pesquisa, que trabalharam de forma independente, sem se comunicar e deram notas 1 a 6 para cada categoria. O índice de acordo entre os juízes tanto no Pré-Teste, como no Pós-Teste podem ser observados na Tabela abaixo, sendo que no Pré-Teste este índice foi de 86\% e no Pós- Teste foi de $90 \%$.

Tabela 1 - Índice de Acordo entre Juizes no Pré e Pós-Testes.

\begin{tabular}{l|c|c}
\hline SUJEITOS & PRÉ-TESTE & PÓS-TESTE \\
\hline \multicolumn{3}{|c}{ Índice \% } \\
\hline S1 & 83 & 89 \\
S2 & 80 & 86 \\
S3 & 79 & 76 \\
S4 & 82 & 97 \\
S5 & 100 & 100 \\
S6 & 85 & 100 \\
S7 & 92 & 94 \\
S8 & 74 & 81 \\
S9 & 84 & 100 \\
S10 & 87 & 94 \\
S11 & 97 & 90 \\
S12 & 100 & 87 \\
\hline TOTAL & $\mathbf{8 6 \%}$ & $\mathbf{9 0 \%}$ \\
\hline
\end{tabular}

Para as sessões de treino foi utilizada uma Ficha de Observação denominada Ficha de Colaboração/ Participação do Par, com o objetivo de avaliar os comportamentos de participação do par, em relação ao sujeito e em relação à pesquisadora durante as sessões de Treino. Esta ficha foi composta de 15 categorias positivas e 2 categorias negativas, descritas a seguir.

\section{Categorias Positivas}

Categoria 1- Comenta o que a pesquisadora falou: Emite comentários após explicações fornecidas pela pesquisadora. Exemplo: "Eu conheço o Jogo Lince, mas nunca fiz Tabela" (S2, na $2^{a}$ sessão de Treino. "Legal, eu já fiz a Tabela, você vai gostar" (S1 respondendo para S2 , após instrução dada pela pesquisadora.)

Categoria 2- Colabora: Observar comportamentos de colaboração do par em relação ao sujeito. Exemplo: "Como escreve história?" (S5 perguntando para sua dupla, na $1^{\text {a }}$ sessão de Treino) "Deixa eu ver; você escreveu certo. É melhor você colocar A história..." (S6 respondendo para S5 demonstrando um comportamento de colaboração). 
Categoria 3- Corrige erro: Observar se o par apresenta comportamentos de correção da escrita do sujeito. Exemplo: "É teitava, B? O certo é deitava". (S6, corrigindo S5 na $1^{\text {a }}$ sessão de Treino.)

Categoria 4- Pede ajuda: Observar se o par pede ajuda para o sujeito e à pesquisadora. Exemplo: "É chego ou chegado que se fala?" (S8 perguntando para pesquisadora na $1^{a}$ sessão de Treino).

Categoria 5- Faz pergunta: Observar se o par faz perguntas ao sujeito e à pesquisadora. Exemplo: "Quando o pássaro vai embora é pra nunca mais voltar? (S10 perguntando para S9, na $1^{\text {a }}$ sessão de Treino).

Categoria 6- Oferece ajuda: Observar se o par oferece ajuda ao sujeito, em situação na qual este necessite de ajuda. Exemplo: "M., escreve aí: Era um rei que teve uma linda idéia, mas não queria guardá-la só para si" (S12 ditando o início do texto para S11, quando este disse que não sabia como começar).

Categoria 7- Pede retroinformação (feedback): Observar se a dupla solicita alguma informação após explicação dada pela pesquisadora. Exemplo: "O passeio tem que ser de bicicleta? Não pode ser de carro?" (S8, 4 sessão de Treino, após proposta para elaboração de história, dada pela pesquisadora).

Categoria 8- Responde a pergunta do colega: Observar se as perguntas feitas pelo sujeito são respondidas pela dupla. Exemplo: "O que vamos escrever?" (S7, 4 $4^{\text {a }}$ sessão de Treino perguntando para S8 a respeito do texto que precisavam elaborar.). "Vamos fazer que você foi dormir na minha casa e que ia ter um piquenique..." (resposta de S8, para S7)

Categoria 9- Presta atenção ao colega: Observar se a dupla se mantém atenta ao colega durante a atividade a ser realizada, auxiliando-o quando necessário. Exemplo: "L, coloca ventinho no código do /k/, você esqueceu." (S4 demonstrando-se atento à atividade de S3, na $3^{\mathrm{a}}$ sessão de Treino durante a elaboração da Tabela Fonema-Grafema).

Categoria 10- Solicita atenção: Observar se a dupla solicita atenção do sujeito durante a realização da atividade. Exemplo: "T, você não coloca o que eu falo..." (S2, dirigindo-se a S1 na $3^{a}$ sessão de treino).

Categoria 11- Dá informação: Observar se a dupla fornece informação para facilitar o desempenho do sujeito durante o Treino. Exemplo: "T, no meio da frase não se usa letra maiúscula." (S2 fornecendo informação para S1, $7^{\text {a }}$ sessão de Treino).

Categoria 12- Pede informação: Observar se o par pede informação ao sujeito durante a realização da atividade. Exemplo: "B., como era mesmo? Era na seca? Ah, vai na seca mesmo." (S6, solicitando informação para S5, na $1^{\text {a }}$ sessão de Treino).

Categoria 13- Elogia o colega: Observar se a dupla faz algum elogio ao colega, enquanto as atividades são realizadas. Exemplo: "Nosso texto está curto, mas você vai ver o conteúdo.. nós somos os bons!" (S11 referindo-se ao texto que estavam fazendo na $5^{a}$ sessão de Treino) S12 complementa : "É, nós somos mesmo, os bons..."

Categoria 14 - Expressa humor: Observar se a dupla apresenta comportamentos indicativos de humor. Exemplo: "Inês, você já ouviu falar da piada do não, nem eu?" (S8, dirigindo-se à pesquisadora na $8^{\text {a }}$ sessão de Treino.)

Categoria 15- Expressa satisfação: Observar se a dupla apresenta comportamentos que expressem satisfação, como por exemplo, comentários positivos ou sorrisos durante as sessões de 
Treino. Exemplo: "Estamos hiper-adiantados! O nosso texto está legal!" (S12 na $1^{\text {a }}$ sessão de Treino, enquanto S11 concorda e sorri).

\section{Categorias negativas}

Categoria 1- Comportamentos antagônicos com cooperação em relação à pesquisadora: Observar se as duplas ou um membro da dupla apresentam comportamentos que demonstrem falta de cooperação em relação à pesquisadora. Exemplo: "Detestei esta história, me deu sono!" (S3, na ta sessão de Treino).

Categoria 2 - Comportamentos antagônicos com cooperação em relação ao par: Observar se as duplas ou um membro da dupla apresentam comportamentos que demonstrem falta de cooperação em relação ao colega. Exemplo: "Que letra feia! O quê você escreveu? Ah, com essa lerdeza..." (S2 referindo-se a S1, na $8^{\text {a }}$ sessão de Treino).

A pesquisadora e a auxiliar de pesquisa, além das notas, também anotaram os exemplos e comentários das duplas. A ficha de observação está apresentada a seguir.

Ficha de observação de Colaboração/ Participação do sujeito em relação ao par.

Sujeito:

Par:

Sessão de Treino:

\begin{tabular}{|l|l|l|l|l|l|l|}
\hline Colaboração/ Participação do Par & 1 & 2 & 3 & 4 & 5 & 6 \\
\hline Comenta o que a pesquisadora falou & & & & & & \\
\hline Colabora & & & & & & \\
\hline Corrige erro & & & & & & \\
\hline Pede ajuda & & & & & & \\
\hline Faz pergunta & & & & & & \\
\hline Oferece ajuda & & & & & & \\
\hline Pede retroinformação & & & & & & \\
\hline Responde a pergunta do colega & & & & & & \\
\hline Presta atenção ao colega & & & & & & \\
\hline Solicita atenção & & & & & & \\
\hline Dá informação & & & & & & \\
\hline Pede informação & & & & & & \\
\hline Elogia o colega & & & & & & \\
\hline Humor & & & & & & \\
\hline Expressa satisfação & & & & & \\
\hline $\begin{array}{l}\text { Comportamentos antagônicos com a cooperação- } \\
\text { em relação a pesquisadora }\end{array}$ & & & & & \\
\hline $\begin{array}{l}\text { Comportamentos antagônicos com a cooperação- } \\
\text { em relação ao par }\end{array}$ & & & & & \\
\hline
\end{tabular}


Os índices de acordo obtido entre os juizes, em cada uma das oito sessões de Treino aparecem na tabela a seguir, sendo que o índice geral, conforme pode ser constatado, foi de $83 \%$.

Tabela 2- Concordância entre juízes nas sessões de Treino.

\begin{tabular}{l|c}
\hline Sessões & Índice de concordância (\%) \\
\hline $1^{\mathrm{a}}$ & 88 \\
$2^{\mathrm{a}}$ & 87 \\
$3^{\mathrm{a}}$ & 83 \\
$4^{\mathrm{a}}$ & 82 \\
$5^{\mathrm{a}}$ & 76 \\
$6^{\mathrm{a}}$ & 84 \\
$7^{\mathrm{a}}$ & 77 \\
$8^{\mathrm{a}}$ & 92 \\
\hline TOTAL & $\mathbf{8 3 \%}$ \\
\hline
\end{tabular}

Após a análise dos resultados obtidos e constatando-se sua efetividade, pode-se concluir que estas fichas de observação podem ser utilizadas em outras pesquisas a respeito de comportamento cooperativo tanto em situação de clínica como em de sala de aula.

\section{Referências}

Carvalho, A.M.P. Reescrever histórias (individual vs. grupal) e produção de textos na $3^{\text {a }}$ série do $1^{\circ}$ grau. Tese de Doutorado. São Paulo: I.P.USP.,1995.

Carvalho, A.M.P. Adesão ao trabalho de escrita em cooperação e suas relações com a qualidade dos textos produzidos. DOXA- Revista Paulista de Psicologia e Educação, 3 (1-2), 73:84. 1997.

Fernandes, M.I.A.O.S. Redação individual e em cooperação em sujeitos com dificuldades de aprendizagem escolar. Dissertação de Mestrado. Instituto de Psicologia e Fonoaudiologia. Campinas: PUC, 2000. 